Check for updates

Cite this: Chem. Sci, 2019, 10, 8009

๑ All publication charges for this article have been paid for by the Royal Society of Chemistry

Received 21st May 2019

Accepted 10th July 2019

DOI: $10.1039 / c 9 s c 02477 \mathrm{~h}$

rsc.li/chemical-science

\section{Conceptual similarities between zeolites and artificial enzymes $\dagger$}

\author{
Eva M. Gallego, (D) Cecilia Paris, (D) Ángel Cantín, Manuel Moliner (iD \\ and Avelino Corma (D) *
}

\begin{abstract}
By using a Diels-Alder (DA) reaction as a base case, we show that a pure silica zeolite acting as an entropytrapping scaffold can be synthesized with an organic structure directing agent (OSDA) analogue of the transition state (TS) of the DA reaction. A cavity stabilization of the TS is observed with the corresponding decrease in the activation energy of the reaction. A lower enthalpy of activation and a larger decrease in entropy are obtained with the zeolite synthesized with the analogue of the DA TS when compared with other zeolitic structures. Those differences are maintained, while catalytic activity is increased, when active sites are introduced in the zeolite. The catalytic zeolitic system synthesized with the OSDA analogue of the TS shows conceptual similarities with "de novo design" of an artificial enzyme to perform DA reactions, in where a suitable scaffold of existing proteins is chosen, and computationally designed active sites able to catalyze the cycloaddition reaction are introduced.
\end{abstract}

\section{Introduction}

The Diels-Alder (DA) reaction allows the efficient preparation of complex cyclic and polycyclic organic compounds by reacting electron rich 1,3-dienes with electron-deficient dienophiles. The relevance of the reaction is based on the fact that it can generate two $\mathrm{C}-\mathrm{C}$ bonds and up to four stereogenic centers in a single concerted step. ${ }^{1}$ This cycloaddition reaction has played a key role along the years in the chemical industry since its discovery, ${ }^{2}$ covering from the early applications in the context of total synthesis of natural products, ${ }^{3}$ to the recent biomass transformation processes for the selective preparation of aromatic molecules. ${ }^{4}$

DA reaction occurs through a highly ordered transition state (TS). ${ }^{5}$ The reaction can take place by thermal activation, ${ }^{6}$ photochemical irradiation, ${ }^{7}$ and homogeneous ${ }^{8}$ or heterogeneous catalysis, ${ }^{9}$ among others. It is very interesting that up to recently it was thought that DA reaction does not occur in nature since no enzymes were found to catalyse the cycloaddition reaction. However, it is known there are enzymes that catalyse reactions between dienes and dienophiles in cycloaddition processes..$^{10}$ For example, the naturally insecticide Spinosyn A is formed through an enzyme catalysed reaction. The reaction mechanism has been explained by assuming that the cyclic molecule can be constrained within the enzyme environment, and the diene and dienophile will be arranged in a geometry closer to the transition state. ${ }^{11}$ However, since such a constraint will imply a decrease in the entropy of the transition state, this should be compensated by hydrogen bonding with amino acid residues of the active center of the enzyme. If this was so, one could consider that nature may use existing enzymes and make them as the starting point for a general scaffold, which would be evolutionally modified to catalyse a specific reaction, such as cycloaddition reactions. ${ }^{12}$ This line of thought has inspired the synthesis of artificial enzymes, that could be prepared by combining the proper cavity or scaffold and locate there the necessary groups to achieve the hydrogen bonds that will stabilize the TS. ${ }^{13}$ In these cases, a protein with a binding pocket that approaches the two substrates and appropriately places hydrogen bond donor and acceptor, can effectively catalyse DA reactions. Following an analogous way of thinking, catalytic antibodies have been generated to a structure that mimics the pericyclic transition state for these types of reactions. ${ }^{14}$ Even metal ion catalysis has been combined with divers biomolecular scaffolds to promote cycloaddition reactions. ${ }^{15}$ Taking into account all of the above, a solid catalyst suitably designed for a DA reaction should be formed by a scaffold consisting of a cavity that directs the formation and accommodates the transition state, together with the hydrogen bonding required to minimize the enthalpy of activation of the TS during this reaction. In other words, one would like to design a solid catalyst with cavities that could be used as a molecular trap to decrease the entropic barrier of the reaction, while establishing weak interactions between the transition state and
Instituto de Tecnología Química, Universitat Politècnica de València-Consejo Superior de Investigaciones Cientificas, Avenida de los Naranjos $s / n, 46022$ València, Spain.E-mail: acorma@itq.upv.es $\dagger$ Electronic supplementary information (ESI) available. See DOI: $10.1039 / \mathrm{c} 9 \mathrm{sc} 02477 \mathrm{~h}$ 
the surface atoms of the solid catalyst to minimize the enthalpy of the TS $\left(\Delta H^{\neq}\right)$.

Thinking about cavities with molecular dimensions on a solid catalyst, zeolites come right away into the game and, in fact, some work on DA reaction with zeolites has already been published. ${ }^{9,16}$ Probably the first report was made by Dessau, ${ }^{16 c}$ who showed that the DA reaction was catalyzed by ZSM- 5 zeolite at $250-500{ }^{\circ} \mathrm{C}$. Nevertheless, a high reaction temperature $(\geq 250$ $\left.{ }^{\circ} \mathrm{C}\right)^{4,16 c}$ much higher than those needed by artificial enzymes (4$37^{\circ} \mathrm{C}$ ), was required..$^{13 a, 15 a, 17}$ In general, the zeolite catalysts were selected on the bases of the already existing materials and no specific structures that can act as scaffold to direct the transformation of the DA transition state were searched.

We have recently showed that " $a b$ initio" zeolite structures for a particular reaction can be synthesized by using a TS mimic of the reaction as a molecular "template" or organic structure directing agent (OSDA).$^{18}$ If a zeolite is synthesized with such a mimic, it should minimize the free energy of the transition state relative to the reactive intermediate. This should be caused by the confinement effect that will stabilize the TS within the pores of the zeolite, decreasing the activation energy of the reaction. In fact, other remarkable catalytic improvements have been described in the literature dealing on confinement effects in zeolites, such as for the dimethylether carbonylation, ${ }^{19}$ the propane dehydrogenation, ${ }^{20}$ or the acetone condensation reactions, ${ }^{21}$ among others. In these cases, a better TS confinement within specific pockets and/or pores has been described, introducing the "right" fit to minimize the free energy barrier of reaction. Such an effect will be more notorious for reactions occurring at lower temperatures, since then the compensating contribution of entropic effects within the zeolite pores will be less important. ${ }^{22}$

Following this principle, it should be achievable to synthesize a zeolite whose cavities can act as scaffolds for a given DA reaction, using as OSDA a mimic of the DA reaction product, since transition state and reaction product are very close. If zeolite crystallization is successful, then the synthesized zeolite should already correspond to the scaffold for that reaction. Nevertheless, it should be possible to go one-step further if during the synthesis or by post synthesis methods, the required centers could be introduced into the framework structure to enhance the catalytic activity of the solid catalyst.

While it is true that structure flexibility of the cavities of the zeolite is smaller than either the scaffolds of enzymes, artificial enzymes and antibodies, designed accuracy appears to correlate with scaffold rigidity. ${ }^{13 a, 23}$ Then, the control over the backbone conformation that we have in the zeolite synthesized with the mimic, could be helpful for the design of a good solid catalyst.

Herein, we demonstrate the enhancement of the catalytic activity for the DA reaction between 1,3-cyclohexadiene and $\mathrm{N}$ methylmaleimide when using a specific zeolite, ITQ-17 (BEC structure), which has been synthesized using an OSDA that mimics the DA product (see Fig. 1). In fact, the pure silica form of the BEC zeolite already shows a $\sim 2-2.5$ fold increase of the initial reaction rate compared to the thermal reaction or the reaction in the presence of other related pure silica microporous materials (i.e. Beta zeolite). Notice that the activity due to

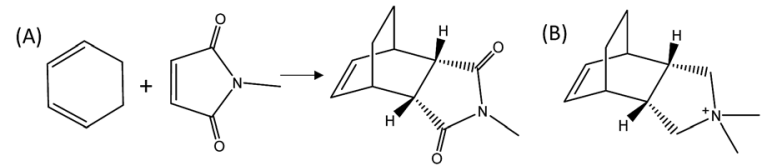

Fig. 1 DA reaction between 1,3-cyclohexadiene and $N$-methylmaleimide (A) and (3aR,4S,7R,7aS)-2,2-dimethyl-2,3,3a,4,7,7a-hexahydro- $1 \mathrm{H}-4,7$-ethanoisoindol-2-ium molecule as OSDA mimic of the DA adduct (B).

the confinement overcomes the activity of the pure silica MCM41 with a very large surface area, when working at low temperatures. The achieved data provide evidence that while entropic barriers are more positive on MCM-41 $\left(\sim 50 \mathrm{~J} \mathrm{~mol}^{-1} \mathrm{~K}^{-1}\right.$ more positive), the much lower enthalpic barrier in BEC $\left(\sim 20 \mathrm{~kJ} \mathrm{~mol}^{-1}\right.$ lower) overcomes the entropic barrier at low temperatures. These results put in relevance the importance of the stabilization effects achieved by the catalyst structures depending on the reaction temperature, clearly influencing their transition state enthalpies and entropies. Finally, the reaction rate of the DA process can also be remarkably increased by introducing well-defined single metal atom sites, such as Ti, within the framework of the optimized zeolite BEC microreactor, as it occurs with artificial enzymes.

\section{Experimental section}

\subsection{Zeolite synthesis}

\subsubsection{Synthesis of pure silica materials}

Si-BEC. The synthesis of the pure silica BEC zeolite was carried out using the OSDA mimic of the DA-adduct (see Fig. 1B), according to the recipe described in the literature. ${ }^{24}$ The final molar composition of the gel was: $\mathrm{SiO}_{2}: 0.54$ OSDA(OH):0.25 KOH:0.54 NH $\mathrm{N}_{4} \mathrm{~F}: 7.25 \mathrm{H}_{2} \mathrm{O}$. The gel was heated in Teflon lined stainless steel autoclaves for 14 days at $175{ }^{\circ} \mathrm{C}$, yielding to a white solid after filtration and extensive washing with boiling water and drying at $100^{\circ} \mathrm{C}$ overnight. The solid was calcined in air at $580{ }^{\circ} \mathrm{C}$ during 6 hours to remove the organic molecules occluded during the hydrothermal synthesis.

The calcined Si-BEC material was ion exchanged with a $1.0 \mathrm{M}$ ammonium chloride solution ( $1.0 \mathrm{~g}$ zeolite in $10 \mathrm{ml}$ solution) at $80{ }^{\circ} \mathrm{C}$ for $3 \mathrm{~h}$. The sample was filtered and washed with deionized water. Finally, the calcination was carried out in air at $400{ }^{\circ} \mathrm{C}$ for $4 \mathrm{~h}$.

Si-Beta. $6.73 \mathrm{~g}$ of tetraethylammonium hydroxide (TEAOH, Sigma-Aldrich, $35 \% \mathrm{wt}$ ) was mixed with $4.8 \mathrm{~g}$ of a colloidal silica suspension (Ludox AS-40, Sigma-Aldrich, $40 \% \mathrm{wt}$ ). The resultant mixture was stirred for 1 hour and, afterwards, $2.96 \mathrm{~g}$ of an aqueous solution of $\mathrm{NH}_{4} \mathrm{~F}(20 \% \mathrm{wt})$ was added to the gel and stirred for $4 \mathrm{~h}$. The evaporation of the excess of water was carried out in a vacuum freeze-drying chamber. The final composition of the gel was: $\mathrm{SiO}_{2}: 0.5$ TEAOH:0.5 $\mathrm{NH}_{4} \mathrm{~F}: 1 \mathrm{H}_{2} \mathrm{O}$. The gel was heated at $150{ }^{\circ} \mathrm{C}$ in Teflon lined stainless steel autoclaves for 48 hours, and the resultant solid was filtered, washed and dried at $100{ }^{\circ} \mathrm{C}$. The solid was calcined in air at 
$580{ }^{\circ} \mathrm{C}$ during 6 hours to remove the organic molecules occluded during the hydrothermal synthesis.

Si-MCM-41. $4.74 \mathrm{~g}$ of an aqueous solution of tetramethylammonium hydroxide (TMAOH, Sigma Aldrich, 25\% wt) was mixed with $3.1 \mathrm{~g}$ of hexadecyltrimethylammonium bromide (CTMABr, Sigma-Aldrich, 98\% wt) and $18.4 \mathrm{~g}$ of double-distilled water. The resulting mixture was maintained under stirring at $40{ }^{\circ} \mathrm{C}$ until a clear solution was obtained. Finally, $3.0 \mathrm{~g}$ of aerosil (Sigma-Aldrich) was added as silica source. The mixture was stirred until evaporation of the excess of water. The composition of the final synthesis gel was: $\mathrm{SiO}_{2}: 0.26 \mathrm{TMAOH}: 0.17 \mathrm{CTMABr}: 24.4$ $\mathrm{H}_{2} \mathrm{O}$. The final gel was charged into a stainless steel autoclave with a Teflon liner, and the crystallization was conducted at $150{ }^{\circ} \mathrm{C}$ for $48 \mathrm{~h}$ under static conditions. The resultant solid was filtered, washed with water, and dried at $100{ }^{\circ} \mathrm{C}$. Calcination of the sample to remove the organic molecules occluded within the solid particles was performed in air at $580{ }^{\circ} \mathrm{C}$ for $8 \mathrm{~h}$.

2.1.2. Synthesis of titanium-containing silicate materials

Ti-BEC. The synthesis of the Ti-containing BEC zeolite was carried out according to the recipe described in the literature. ${ }^{25}$ The final molar composition of the gel was: $\mathrm{SiO}_{2}: 0.004 \mathrm{TiO}_{2}: 0.25$ OSDA:0.5 $\mathrm{NH}_{4} \mathrm{~F}: 2 \mathrm{H}_{2} \mathrm{O}$. The gel was heated in Teflon lined stainless steel autoclaves for 14 days at $175^{\circ} \mathrm{C}$, and the resultant solid was filtered, washed and dried at $100{ }^{\circ} \mathrm{C}$ overnight. The solid was calcined in air at $580{ }^{\circ} \mathrm{C}$ during 6 hours to remove the organic molecules occluded during the hydrothermal synthesis.

Ti-Beta. The synthesis of the Ti-Beta zeolite was carried out according to slight modifications of the recipe described in the literature. ${ }^{26} 1.81 \mathrm{~g}$ of tetraethylammonium hydroxide (TEAOH, Sigma-Aldrich, $35 \% \mathrm{wt}$ ) was mixed with $36 \mathrm{mg}$ of titanium ethoxide [ $\mathrm{Ti}\left(\mathrm{C}_{2} \mathrm{H}_{5} \mathrm{O}\right)_{4}$, Alfa Aesar] and $1.2 \mathrm{~g}$ of a colloidal silica suspension (Ludox AS-40, Sigma-Aldrich, 40\% wt). The resultant mixture was stirred for 1 hour and, afterwards, $1.55 \mathrm{~g}$ of an aqueous solution of $\mathrm{NH}_{4} \mathrm{~F}(10 \% \mathrm{wt})$ was added to the gel, and the mixture was stirred until evaporation of the excess of water. The final composition of the gel was: $\mathrm{SiO}_{2}: 0.02$ Ti:0.54 TEAOH:0.54 $\mathrm{NH}_{4} \mathrm{~F}: 5 \mathrm{H}_{2} \mathrm{O}$. The gel was heated at $175^{\circ} \mathrm{C}$ in Teflon lined stainless steel autoclaves for 10 days, and the resultant solid was filtered, washed and dried at $100{ }^{\circ} \mathrm{C}$. The solid was calcined in air at $580{ }^{\circ} \mathrm{C}$ during 6 hours to remove the organic molecules occluded during the hydrothermal synthesis.

$T i-M C M-41.4 .74 \mathrm{~g}$ of an aqueous solution of tetramethylammonium hydroxide (TMAOH, Sigma Aldrich, 25\% wt) was mixed with $3.1 \mathrm{~g}$ of hexadecyltrimethylammonium bromide (CTMABr, Sigma-Aldrich, 98\% wt), $55 \mathrm{mg}$ of titanium ethoxide $\left[\mathrm{Ti}\left(\mathrm{C}_{2} \mathrm{H}_{5} \mathrm{O}\right)_{4}\right.$, Alfa Aesar] and $18.4 \mathrm{~g}$ of double-distilled water. The resulting mixture was maintained under stirring at $40{ }^{\circ} \mathrm{C}$ until a clear solution was obtained. Finally, $3.0 \mathrm{~g}$ of aerosil (Sigma Aldrich) was added as silica source. The mixture was stirred until evaporation of the excess of water. The composition of the final synthesis gel was: $\mathrm{SiO}_{2}: 0.005$ Ti:0.26 TMAOH:0.17 CTMABr:24.4 $\mathrm{H}_{2} \mathrm{O}$. The resultant gel was charged into a stainless steel autoclave with a Teflon liner, and the crystallization was conducted at $150{ }^{\circ} \mathrm{C}$ for $48 \mathrm{~h}$ under static conditions. The achieved solid was filtered, washed with water, and dried at $100{ }^{\circ} \mathrm{C}$. Calcination of the sample to remove the organic molecules occluded within the solid particles was performed in air at $580{ }^{\circ} \mathrm{C}$ for $8 \mathrm{~h}$.

\subsection{Characterization}

Synthesized samples were characterized by powder X-ray diffraction (PXRD) measurements collected on a multisample Philips X'Pert diffractometer equipped with a graphite monochromator, operating at $40 \mathrm{kV}$ and $35 \mathrm{~mA}$, and using $\mathrm{Cu} \mathrm{K}_{\alpha}$ radiation $(\lambda=0.1542 \mathrm{~nm})$.

The chemical analysis was determined by a Varian 715-ES ICP-Optical Emission spectrometer, after dissolution of the solids in $\mathrm{HNO}_{3} / \mathrm{HCl} / \mathrm{HF}$ aqueous solution.

The morphology of the samples was studied with a FieldEmission Scanning Electron Microscopy (FESEM) using a ZEISS Ultra-55 microscope.

Nitrogen adsorption isotherms at $-196^{\circ} \mathrm{C}$ were measured on a Micromeritics ASAP 2020 with a manometric adsorption analyzer to determinate the textural properties of the samples.

The UV-Vis spectra were collected using a Varian Cary 5 spectrometer equipped with a diffuse reflectance accessory.

\subsection{Diels-Alder reaction}

$30 \mathrm{mg}$ of each catalyst was activated under vacuum at $150{ }^{\circ} \mathrm{C}$ for 3 hours. After cooling down the solid at room temperature under $\mathrm{N}_{2}$ atmosphere, $22.9 \mathrm{mg}$ of $\mathrm{N}$-methylmaleimide (0.20 mmol; Sigma-Aldrich, $97 \%$ ) and $2 \mathrm{ml}$ of $\mathrm{CDCl}_{3}$ were added. The mixture was stirred and the temperature fixed at 60, 80 and $100{ }^{\circ} \mathrm{C}$. Then, $25 \mu \mathrm{l}$ of freshly distilled 1,3-cyclohexadiene (0.26 mmol, Sigma-Aldrich, 96\%) was added via syringe. 1,4Dinitrobenzene (Sigma-Aldrich, 98\%) was used as internal standard. The samples were taken at different reaction times, and they were analyzed by liquid ${ }^{1} \mathrm{H}$ NMR to obtain initial rates and their respective rate constants (see ${ }^{1} \mathrm{H}$ NMR spectra in Fig. S1†).

The DA reaction between 1,3-cyclohexadiene and $N$-methylmaleimide follows a second-order kinetics (first-order in both Diels-Alder reactants). According to this, it is possible to obtain the reaction rate constant $(k)$ and the initial rates for each catalyst at given temperatures.

The activation energy, $E_{\mathrm{a}}$, can be calculated from the Arrhenius equation:

$$
k=A \mathrm{e}^{-E_{\mathrm{a}} / R T}
$$

where: $k$ is the observed rate constant; $A$ is the pre-exponential factor; $E_{\mathrm{a}}$ is the activation energy $\left(\mathrm{J} \mathrm{mol}^{-1}\right) ; R$ is the universal gas constant (8.314 $\mathrm{J} \mathrm{mol}^{-1} \mathrm{~K}^{-1}$ ); and $T$ is the temperature $(\mathrm{K})$.

The eqn (1) can be linearized by the logarithmic transformation of the dependent variable:

$$
\ln (k)=\ln (A)-\frac{E_{\mathrm{a}}}{R}\left(\frac{1}{T}\right)
$$

Thus, a plot of $\ln (k)$ versus $1 / T$ allows the calculation of the pre-exponential $A$ factor and the activation energy $\left(E_{\mathrm{a}}\right)$. 
The enthalpy, $\Delta H^{\neq}$, and the entropy, $\Delta S^{\neq}$, can be calculated from the Eyring-Polanyi equation:

$$
k=\frac{k_{\mathrm{B}} T}{h} \mathrm{e}^{-\frac{\Delta G^{*}}{R T}}
$$

where: $k$ is the observed rate constant; $k_{\mathrm{B}}$ is the Boltzmann constant $\left(1.381 \times 10^{-23} \mathrm{~J} \mathrm{~K}^{-1}\right) ; T$ is the temperature $(\mathrm{K}) ; h$ is the Planck's constant $\left(6.626 \times 10^{-34} \mathrm{~J} \mathrm{~s}\right) ; \Delta G^{\neq}$is the Gibbs energy of activation $\left(\mathrm{J} \mathrm{mol}^{-1}\right) ; R$ is the universal gas constant $(8.314 \mathrm{~J}$ $\mathrm{mol}^{-1} \mathrm{~K}^{-1}$ ); and $T$ is the temperature (K).

The Gibbs energy of activation during a reaction is equal to the change in the enthalpy minus the product of the temperature and the change in the entropy of the system.

$$
\Delta G^{\neq}=\Delta H^{\neq}-T \Delta S^{\neq}
$$

Therefore, the combination of eqn (3) and (4) can be linearized as follows:

$$
\ln \left(\frac{k}{T}\right)=\frac{-\Delta H^{\ddagger}}{R}\left(\frac{1}{T}\right)+\ln \left(\frac{k_{\mathrm{B}}}{h}\right)+\frac{\Delta S^{\ddagger}}{R}
$$

Thus, a plot of $\ln (k / T)$ versus $1 / T$ produces a straight line with gradient equal to $-\Delta H^{\neq} / R$ and with a $y$-intercept of $\ln \left(k_{\mathrm{B}} / h\right)+$ $\Delta S^{\neq} / R$.

\section{Results and discussion}

To prove the concept, we have used a mimic of the product formed during the DA reaction between 1,3-cyclohexadiene and $\mathrm{N}$ methylmaleimide (see Fig. 1A). The chosen OSDA, ( $3 \mathrm{a} R, 4 S, 7 R, 7 \mathrm{a} S)$ 2,2-dimethyl-2,3,3a,4,7,7a-hexahydro- $1 \mathrm{H}$-4,7-ethanoisoindol-2-ium molecule (see Fig. 1B), corresponds to the DA product and, it is well-known that the TS and the final product in a DA reaction are very similar. ${ }^{27}$ The use of this organic molecule as OSDA has allowed the efficient crystallization of the pure silica BEC structure (Si-BEC) ${ }^{24}$ This material presents a three-directional large pore system, in where the three channels cross in a larger cavity-like void space. The zeolite BEC synthesized is a polymorph of the commercially manufactured Beta zeolite (BEA). They are polymorphs composed by the same crystallographic layer, which has been arranged under different stacking order for each material, resulting in related but different crystalline structures (see Fig. $\mathrm{S} 2 \dagger){ }^{28}$ Though both polymorphs are closely related, the specific difference in the crystalline structure should have an impact on the stabilization of the DA TS and the desired scaffold specify could be well tested with these two zeolites. Therefore, we have first synthesized pure silica BEC (Si-BEC) and pure silica BEA (Si-BEA) in where no framework specific potentially active sites have been introduced. In this case, the DA TS stabilization should be only accomplished by confinement and dispersion forces, as mastered by using the mimic of DA as organic template that results in the synthesis of the BEC structure.

As said before, both zeolites have been obtained in the pure silica form, with very good crystallinities (see PXRD patterns in Fig. 2a) and with similar crystallite size (see Table 1). Indeed, SiBEA shows small crystallites of $0.2-0.3 \mu \mathrm{m}$ that are
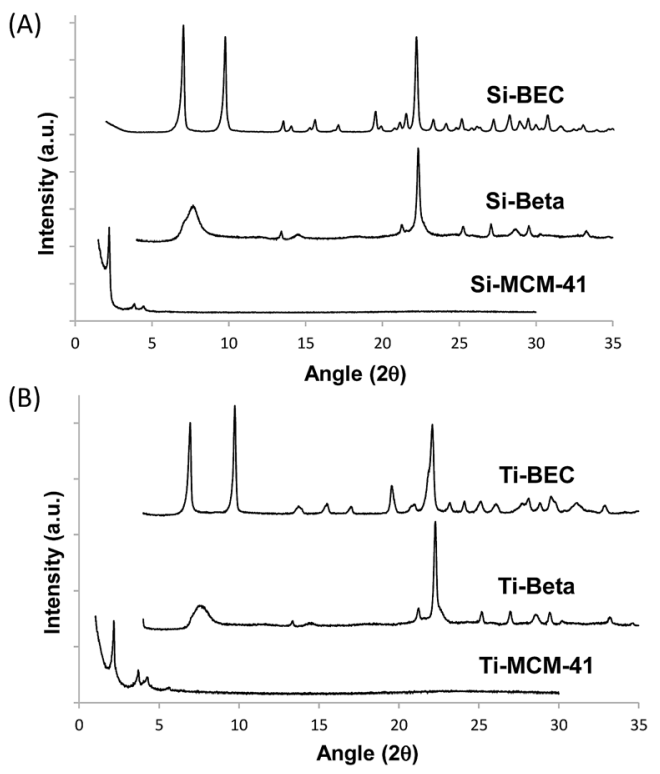

Fig. 2 PXRD patterns of the calcined pure silica (A) and Ti-containing microporous and mesoporous materials (B).

agglomerated in the form of 1-2 $\mu \mathrm{m}$ nanoparticles, while Si-BEC is formed by the aggregation of tetragonal crystals with size of $0.2-1 \mu \mathrm{m}$ (see Fig. S3†). When the activity for the DA condensation of 1,3-cyclohexadiene and $N$-methylmaleimide is evaluated at $60{ }^{\circ} \mathrm{C}$, the pure silica form of the BEC zeolite already shows a $\sim 2.5$ fold increase of the initial reaction rate compared to the thermal reaction or when using the related pure Beta zeolite. The results show that even if a confinement by the nanopores of the solid catalyst already enhances the rate of the reaction, the larger structural specificity achieved by the scaffold synthesized with the mimic OSDA, has an impact on the rate of reaction.

At this point, it is worth noting that some authors have described that periodically ordered mesoporous materials, i.e. MCM-41 or FSM-16, perform better than some crystalline silicate zeolites for different DA reactions, fact that was explained by the promoter effect of the weak acidity of external silanols. ${ }^{9 b}$ These ordered mesoporous materials show extended pores compared to those of zeolites, in general being ranged between 20-30 A. Thus, for comparison purposes, a well-ordered mesoporous pure silica MCM-41 material was prepared (see details in Experimental section). The obtained Si-MCM-41 material presents the standard PXRD pattern of a well-ordered mesoporous MCM-41, as revealed by the presence of an intense peak centered at $\sim 2$ degrees and two smaller peaks between $\sim 4-5$ degrees (see Si-MCM-41 in Fig. 2A). In addition, the Si-MCM-41 shows a higher BET surface area $\left(\sim 730 \mathrm{~m}^{2} \mathrm{~g}^{-1}\right.$, see Table 1$)$ than the previously synthesized zeolites. According to this, it was asserted that the Si-MCM-41 shows an improvement in the catalytic activity for the $\mathrm{DA}$ reaction at $60{ }^{\circ} \mathrm{C}$ compared to the Beta zeolite (see Fig. 3A).

However, the Si-BEC catalyst, which was synthesized using the mimic of the DA adduct as OSDA, performs clearly better than the mesoporous Si-MCM-41 (see Fig. 3A), presenting 
Table 1 Physico-chemical properties and relative initial reaction rates $\left(r_{0} / r_{\text {othermal }}\right)$ at $60^{\circ} \mathrm{C}$ and $100{ }^{\circ} \mathrm{C}$ for the silicate and titanosilicate materials. Reaction conditions: $0.26 \mathrm{mmol} 1,3$-cyclohexadiene, $0.20 \mathrm{mmol} \mathrm{N}$-methylmaleimide, $2 \mathrm{ml} \mathrm{CDCl} 3,30$ mg of catalyst. The $r_{0} / r_{0 t h e r m a l}$ ratios are the relative initial rates achieved for each solid divided by the initial rate of the DA reaction without catalyst (thermal reaction) at a given temperature

\begin{tabular}{|c|c|c|c|c|c|c|c|}
\hline Sample & Crystal size $(\mu \mathrm{m})$ & $\mathrm{Si} / \mathrm{Ti}$ & $\begin{array}{l}\text { BET surface area } \\
\left(\mathrm{m}^{2} \mathrm{~g}^{-1}\right)\end{array}$ & $\begin{array}{l}\text { Ext. surface area } \\
\left(\mathrm{m}^{2} \mathrm{~g}^{-1}\right)\end{array}$ & $\begin{array}{l}\text { Micropore area } \\
\left(\mathrm{m}^{2} \mathrm{~g}^{-1}\right)\end{array}$ & $\begin{array}{l}r_{0} / r_{\text {othermal }}(60 \\
\left.{ }^{\circ} \mathrm{C}\right)\end{array}$ & $\begin{array}{l}r_{0} / r_{\text {othermal }}(100 \\
\left.{ }^{\circ} \mathrm{C}\right)\end{array}$ \\
\hline Si-MCM-41 & $0.05-0.10$ & - & 731 & - & - & 1.6 & 1.7 \\
\hline Si-Beta & $0.2-0.3$ & - & 504 & 116 & 388 & 1.3 & 1.1 \\
\hline Si-BEC & $0.2 \times 1$ & - & 389 & 24 & 365 & 2.5 & 1.4 \\
\hline Ti-MCM-41 & $0.05-0.10$ & 180 & 968 & - & - & 1.7 & 1.6 \\
\hline Ti-Beta & 0.5 & 50 & 494 & 25 & 469 & 1.7 & - \\
\hline Ti-BEC & $0.4-0.5$ & 240 & 500 & 40 & 460 & 3.7 & 1.9 \\
\hline
\end{tabular}

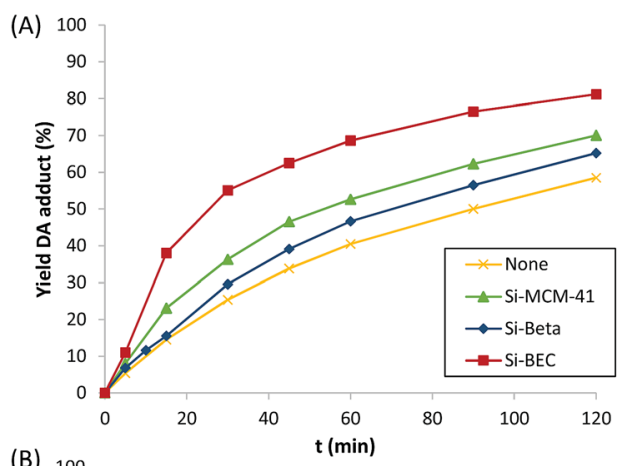

(B) 100

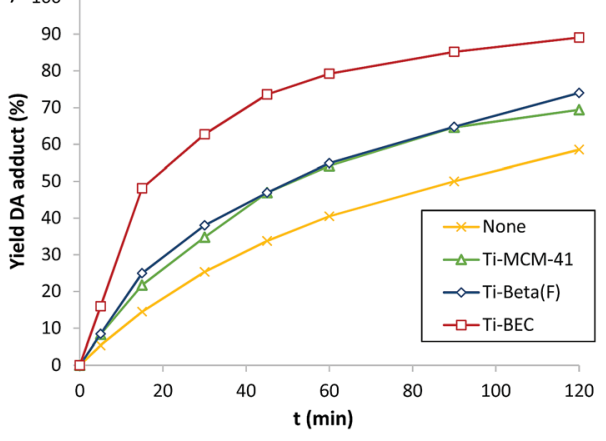

Fig. 3 Catalytic activity for the Diels-Alder reaction using different silicate (A) and titanosilicate materials (B). Reaction conditions: $0.26 \mathrm{mmol} 1,3$-cyclohexadiene, $0.20 \mathrm{mmol} \mathrm{N}$-methylmaleimide, $2 \mathrm{ml}$ $\mathrm{CDCl}_{3}, 30 \mathrm{mg}$ of catalyst, and $T=60^{\circ} \mathrm{C}$.

a 1.7 -fold increase of the initial reaction rate when the DA is carried out at $60{ }^{\circ} \mathrm{C}$ (see Table 1). The results obtained from the synthesis and catalytic evaluation of the different pure silica materials, shows the catalytic benefit of using an "imprinted" scaffold to facilitate the DA reaction in an analogous way as catalytic antibodies do for these processes.

As stated above, the differences in the macroscopic catalytic behavior observed should be related with the larger stabilization of the TS of the reaction within the scaffold of the Si-BEC zeolite, with the corresponding decrease of the activation energy of the reaction. Then, the calculated activation energies $\left(E_{\mathrm{a}}\right)$ give 18,27 and $36 \mathrm{~kJ} \mathrm{~mol}^{-1}$ for the reaction carried out with Si-BEC, Si-BEA and Si-MCM-41, respectively (see linearized Arrhenius plots in Fig. $\mathrm{S} 4 \mathrm{~A} \uparrow$ and calculated $E_{\mathrm{a}}$ values in Table 2). Moreover, the Eyring-Polanyi approximation (see Fig. 4A) gives enthalpies of activation of 15,24 and $33 \mathrm{~kJ} \mathrm{~mol}^{-1}$, respectively (see Table 2), while the decrease in entropy is remarkably higher for the Si-BEC zeolite $\left(-247 \mathrm{~kJ} \mathrm{~mol}^{-1} \mathrm{~K}^{-1}\right.$, see Table 2).

The kinetic parameters strongly support the benefit of using a zeolitic scaffold synthesized by using the TS mimic template as OSDA. According to the previous results, it could be argued that the catalytic improvement for the DA reaction was already achieved only by confinement, in particular when the reaction is carried out at low temperatures. Now, we can proceed with the zeolite as in the case of synthetic enzymes, by introducing potentially active groups within the scaffold. This has been done here introducing Lewis acid sites (i.e. Ti) within the zeolite framework by direct synthesis. This metal was already observed to be an active site in zeolites for DA reactions catalysis. ${ }^{9 c}$ If this is so, the preparation of the BEC zeolite including isolated Lewis acid sites within its crystalline framework could also enhance the catalytic activity for the DA reaction. Having that in mind, the titanosilicate form of the BEC zeolite has been prepared, ${ }^{25}$ together with the titanosilicate forms of Beta and MCM-41 zeolites for comparison purposes (see Experimental details $\dagger){ }^{26}$ The physico-chemical characteristics of Ti-BEC, Ti-BEA and Ti-MCM-41 are summarized in Table 1. Interestingly, UV-Visible spectra for these materials show that most of the $\mathrm{Ti}$ is tetrahedrally-coordinated in framework positions (see bands centered at $\sim 220-230 \mathrm{~nm}$ in Fig. S6†). ${ }^{29}$

The catalytic results for the DA reaction show further improvement with all catalysts when $\mathrm{Ti}$ is incorporated (see Fig. 3B), being this increase relatively higher for the Ti zeolites (see $r_{0} / r_{\text {othermal }}$ at $60{ }^{\circ} \mathrm{C}$ in Table 1 ). Moreover, the activation energy is still lower for the Ti-BEC (see linearized Arrhenius

Table 2 Experimental values obtained for activation energies $\left(E_{\mathrm{a}}\right)$ from Arrhenius equation, and enthalpies $\left(\Delta H^{\neq}\right)$and entropies $\left(\Delta S^{\neq}\right)$of TS activation from Eyring-Polanyi equation using different silicate and titanosilicate materials (standard errors in parentheses)

\begin{tabular}{llll}
\hline Sample & $E_{\mathrm{a}}\left(\mathrm{J} \mathrm{mol}^{-1}\right)( \pm 3.5)$ & $\begin{array}{l}\Delta H^{\neq}(\mathrm{kJ} \\
\left.\mathrm{mol}^{-1}\right)( \pm 3.5)\end{array}$ & $\begin{array}{l}\Delta S^{\neq}(\mathrm{J} \\
\left.\mathrm{mol}^{-1} \mathrm{~K}^{-1}\right)( \pm 9)\end{array}$ \\
\hline Thermal & 34.4 & 31.5 & -206 \\
Si-MCM-41 & 36.0 & 33.1 & -197 \\
Si-Beta & 27.2 & 24.3 & -225 \\
Si-BEC & 18.4 & 15.5 & -247 \\
Ti-MCM-41 & 32.1 & 29.1 & -209 \\
Ti-BEC & 16.4 & 13.5 & -249
\end{tabular}


(A)

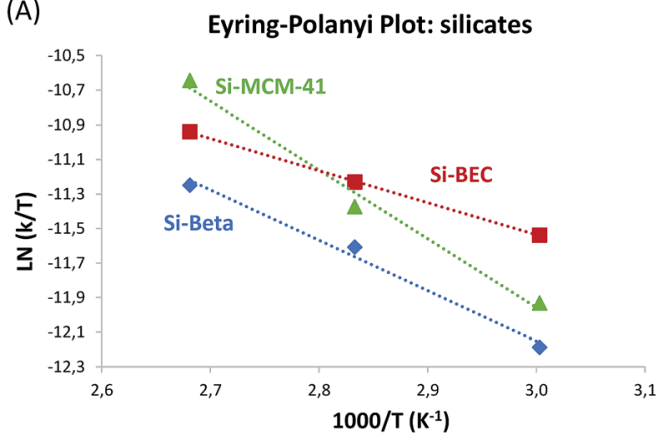

(B)

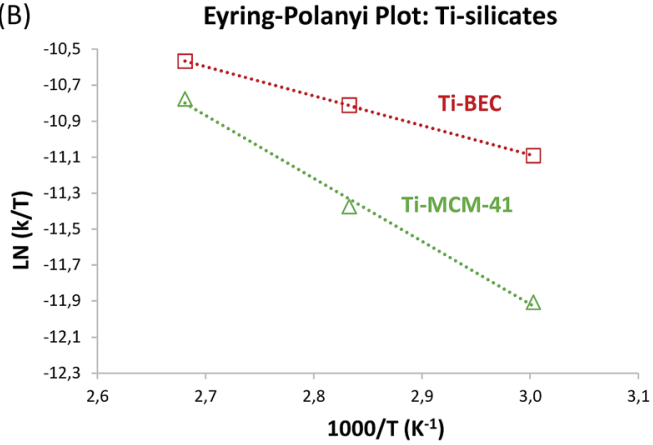

Fig. 4 Linearized Eyring-Polanyi plots of the Diels-Alder reaction for silicates (A) and Ti-silicates (B).

plots in Fig. $\mathrm{S} 4 \mathrm{~B} \dagger$ and calculated $E_{\mathrm{a}}$ values in Table 2). Notice that enthalpies of activation are slightly lower with the Ti containing samples (15.5 and $13.5 \mathrm{~kJ} \mathrm{~mol}^{-1}$ for BEC and Ti-BEC, respectively, see Table 2) while entropies of activation remain practically unaltered $\left(-247\right.$ and $-249 \mathrm{~kJ} \mathrm{~mol}^{-1} \mathrm{~K}^{-1}$ for BEC and Ti-BEC, respectively, see Table 2).

\section{Conclusions}

We have shown the catalytically benefit achieved by synthesizing a zeolite with an OSDA analogue to the TS of a DA reaction in where the crystallized zeolites provides transition state cavity stabilization, acting as the entropy trapping scaffold, in where active sites have been introduced. This is conceptually, at least, not too different from what it is called "de novo design" of an artificial enzyme to perform DA reactions in where a suitable scaffold of existing proteins is chosen and computationally designed active sites able to catalyze the cycloaddition are introduced. If we take into account what it has been said by Preiswerk et $a .^{\mathbf{1 3 a}}$ when working on the impact of scaffold rigidity on the design and evolution of artificial Diels-Alderase: "Because design accuracy appears to correlate with scaffold rigidity, improved control over backbone conformation will likely be the key to future efforts to design more efficient enzymes for divers chemical reactions", it would appear that the smaller framework flexibility of the zeolite would be acceptable for DA reactions, provided that the right scaffold is used as shown in the present work. This approach brings again conceptual parallelism between enzymes and zeolites. ${ }^{30}$

\section{Conflicts of interest}

There are no conflicts to declare.

\section{Acknowledgements}

This work has been supported by the European Union through ERC-AdG-2014-671093 (SynCatMatch), by the Spanish Government-MINECO through "Severo Ochoa” (SEV-2016-0683) and RTI2018-101033, and by La Caixa Foundation through MITSPAIN SEED FUND (LCF/PR/MIT17/11820002). Eva M. Gallego acknowledges "La Caixa - Severo Ochoa" International PhD Fellowships (call 2015). The Electron Microscopy Service of the UPV is acknowledged for their help in sample characterization.

\section{Notes and references}

1 K. C. Nicolaou, S. A. Snyder, T. Montagnon and G. Vassilikogiannakis, Angew. Chem., Int. Ed., 2002, 41, 1668-1698.

2 O. Diels and K. Alder, Justus Liebigs Ann. Chem., 1928, 460, 98-122.

3 (a) R. B. Woodward, F. Sondheimer, D. Taub, K. Heusler and W. M. McLamore, J. Am. Chem. Soc., 1952, 74, 4223-4251; (b) R. B. Woodward, F. E. Bader, H. Bickel, A. J. Frey and R. W. Kierstead, J. Am. Chem. Soc., 1956, 78, 2023-2025.

4 (a) J. J. Pacheco and M. E. Davis, Proc. Natl. Acad. Sci. U. S. A., 2014, 111, 8363-8367; (b) A. Settle, L. Berstis, N. Rorrer, Y. Roman-Leshkov, G. Beckham, R. Richards and D. Vardon, Green Chem., 2017, 19, 3468-3492.

5 M. I. Page and W. P. Jencks, Proc. Natl. Acad. Sci. U. S. A., 1971, 68, 1678-1683.

6 (a) G. M. Ho, C. J. Huang, E. Y. Li, S. K. Hsu, T. Wu, M. M. L. Zulueta, K. B. Wu and S. C. Hung, Sci. Rep., 2016, 6, 35147; (b) A. Marrocchi, L. Minuti, A. Taticchi and H. W. Scheeren, Tetrahedron, 2001, 57, 4959-4965.

7 (a) D. A. Seeley, J. Am. Chem. Soc., 1972, 94, 4378-4380; (b) F. Xu, X. Xiao and T. R. Hoye, J. Am. Chem. Soc., 2017, 139, 8400-8403.

8 (a) S. Yamabe, T. Dai and T. Minato, J. Am. Chem. Soc., 1995, 117, 10994-10997; (b) O. Yilmaz, N. S. Kus, T. Tunç and E. Sahin, J. Mol. Struct., 2015, 1098, 72-75; (c) S. Song, G. Wu, W. Dai, N. Guan and L. Li, J. Mol. Catal. A: Chem., 2016, 420, 134-141.

9 (a) Y. Narayana Murthy and C. Pillai, Synth. Commun., 1991, 21, 783-791; (b) Y. Kubota, H. Ishida, R. Nakamura and Y. Sugi, Stud. Surf. Sci. Catal., 2003, 146, 749-752; (c) M. V. Gomez, A. Cantin, A. Corma and A. de la Hoz, J. Mol. Catal. A: Chem., 2005, 240, 16-21.

10 (a) H. Oikawa and T. Tokiwano, Nat. Prod. Rep., 2004, 21, 321-352; (b) H. Oikawa, Comprehensive Natural Products II, Chem. And Bio., ed. B.-L. Mander and H.-W. Liu, Oxford Elsevier, 2010, pp. 277-314.

11 E. G. Gordeev and V. P. Ananikov, PLoS One, 2015, 10, e0119984.

12 H. Oikawa, Cell Chem. Biol., 2016, 23, 429-430. 
13 (a) N. Preiswerk, T. Beck, J. D. Schulz, P. Milovník, C. Mayer, J. B. Siegel, D. Baker and D. Hilvert, Proc. Natl. Acad. Sci. U. S. A., 2014, 111, 8013-8018; (b) J. B. Siegel, A. Zanghellini, H. M. Lovick, G. Kiss, A. R. Lambert, J. L. St. Clair, J. L. Gallaher, D. Hilvert, M. H. Gelb, B. R. Stoddard, K. N. Houk, F. E. Michael and D. Baker, Science, 2010, 329, 309-313.

14 A. C. Braisted and P. G. Schultz, J. Am. Chem. Soc., 1990, 112, 7430-7431.

15 (a) G. Roelfes and B. L. Feringa, Angew. Chem., Int. Ed., 2005, 44, 3230-3232; (b) M. T. Reetz, Chem. Rec., 2012, 12, 391-406. 16 (a) M. Onaka, R. Yamasaki and T. Ookoshi, Stud. Surf. Sci. Catal., 1999, 121, 139-142; (b) A. Cantín, M. V. Gómez and A. De la Hoz, Beilstein J. Org. Chem., 2016, 12, 2181-2188; (c) R. M. Dessau, J. Chem. Soc., Chem. Commun., 1986, 1167-1168.

17 (a) A. Palma, M. Artelsmair, G. Wu, X. Lu, S. Barrow, N. Uddin, E. Rosta, E. Masson and O. Scherman, Angew. Chem., Int. Ed., 2017, 56, 15688-15692; (b) P. Deuss, G. Popa, A. M. Z. Slawin, W. Laan and P. C. J. Kamer, ChemCatChem, 2013, 5, 1184-1191.

18 (a) E. M. Gallego, M. T. Portilla, C. Paris, A. León-Escamilla, M. Boronat, M. Moliner and A. Corma, Science, 2017, 355, 1051-1054; (b) C. Li, C. Paris, J. Martinez-Triguero, M. Boronat, M. Moliner and A. Corma, Nat. Catal., 2018, 1, 547-554.

19 (a) A. Bhan, A. D. Allian, G. J. Sunley, D. J. Law and E. Iglesia, J. Am. Chem. Soc., 2007, 129, 4919-4924; (b) M. Boronat, C. Martínez and A. Corma, Phys. Chem. Chem. Phys., 2011, 13, 2603-2612.
20 R. Gounder and E. Iglesia, J. Am. Chem. Soc., 2009, 131, 19581971.

21 S. Herrmann and E. Iglesia, J. Catal., 2017, 346, 134-153.

22 R. Gounder and E. Iglesia, Acc. Chem. Res., 2012, 45, 229-238. 23 M. E. Davis, CATTECH, 1997, 1, 19-26.

24 A. Cantin, A. Corma, M. J. Diaz-Cabañas, J. L. Jordá, M. Moliner and F. Rey, Angew. Chem., Int. Ed., 2006, 45, 8013-8015.

25 M. Moliner, P. Serna, A. Cantín, G. Sastre, M. Díaz-Cabañas and A. Corma, J. Phys. Chem. C, 2008, 112, 19547-19554.

26 (a) T. Blasco, M. A. Camblor, A. Corma, P. Esteve, J. M. Guil, A. Martínez, J. A. Perdigón-Melón and S. Valencia, J. Phys. Chem. B, 1998, 102, 75-88; (b) A. Corma, M. T. Navarro and J. Pérez-Pariente, J. Chem. Soc., Chem. Commun., 1994, 147148.

27 M. Yoshizawa, M. Tamura and M. Fujita, Science, 2006, 312, 251-254.

28 J. B. Higgins, R. B. LaPierre, J. L. Schlenker, A. C. Rohrman, J. D. Wood, G. T. Kerr and W. J. Rohrbaugh, Zeolites, 1988, 8, 446-452.

29 M. Moliner and A. Corma, Microporous Mesoporous Mater., 2014, 189, 31-40.

30 (a) M. Boronat, C. Martínez-Sánchez, D. Law and A. Corma, J. Am. Chem. Soc., 2008, 130, 16316-16323; (b) A. Corma, Angew. Chem., Int. Ed., 2016, 55, 6112-6113; (c) R. BermejoDeval, R. S. Assary, E. Nikolla, M. Moliner, Y. RománLeshkov, S. J. Hwang, A. Palsdottir, D. Silverman, R. F. Lobo, L. A. Curtiss and M. E. Davis, Proc. Natl. Acad. Sci. U. S. A., 2012, 109, 9727-9732. 